\title{
Testing Peptide Deamination as a \\ Pathway for Refractory DOM Production in Sediments: Incubation Experiment Results
}

\footnotetext{
T. KOMADA ${ }^{1 *}$, D. BurdigE ${ }^{2}$, H. ABDUlla ${ }^{3}$

${ }^{1}$ Estuary \& Ocean Science Center, San Francisco State University, Tiburon CA, 94920, USA.

${ }^{2}$ Department of Ocean, Earth and Atmospheric Sciences, Old Dominion University, Norfolk, VA 23529, USA.

${ }^{3}$ Department of Physical and Environmental Sciences, Texas A\&M University - Corpus Christi, Corpus Christi TX 78412, USA.

Marine sediments are globally significant sources of dissolved organic matter (DOM) to the water column. However, the connection between sediment DOM dynamics and the oceanic DOM cycle remains elusive, because information is lacking on the molecular composition and reactivity of porewater DOM. To address this knowledge gap, we incubated organic-rich sediments from near-shore and continental-margin environments, and monitored the moleclar composition of DOM with time. These incubations were specifically designed to test two hypotheses: (H1) During protein degradation, a subset of peptides that are not amenable to full hydrolysis is deaminated and accumulates as refractory DOM in the pore water; and (H2) Higher polysaccharide availability lowers the rate of peptide deamination, and increases the concentrations of intact peptides and free amino acids. These experiments were conducted using intertidal sediments from San Francisco Bay, California, and subsurface sediments from Santa Barbara Basin, California Borderland. Three sets of incubations were conducted using each sediment sample: (1) with protein amendment to test $\mathrm{H1}$; (2) with carbohydrate amendment to test $\mathrm{H} 2$; and (3) no amendment (control). Sediment samples were incubated under anoxic conditions in the dark at $19^{\circ} \mathrm{C}$ for approximately 5 months, and DOM composition (peptides, deaminated peptides, carbohydrates) were monitored using IC-OT-FTMS. The outcome of these analyses will be discussed.
} 